\title{
Resilience Builder Program Therapy Addresses Core Social Deficits and Emotion Dysregulation in Youth with High-Functioning Autism Spectrum Disorder
}

\section{Paula A Aduen ${ }^{1}$, Brendan A Rich ${ }^{1 *}$, Lisa Sanchez ${ }^{2}$, Kelly O'Brien ${ }^{2,3}$ and Mary K Alvord ${ }^{2}$}

${ }^{1}$ Department of Psychology, The Catholic University of America, USA

${ }^{2}$ Alvord, Baker \& Associates, LLC, USA

${ }^{3}$ Maryland ADHD Program, University of Maryland-College Park, USA

\begin{abstract}
Background: Impaired social functioning has been shown to be the most persistent and permeating challenge for youth with High-Functioning Autism Spectrum Disorder (HFASD) throughout development; therefore various interventions have been developed to target these social deficits. Research examining the efficacy of manualized social skills intervention programs remains limited and treatment outcome has been predominantly studied in academic research settings. Moreover, conclusions regarding the efficacy of social skills training programs have been mixed; suggesting therapy must address more than just social skills. The present study aimed to address the above research limitations by exploring the effectiveness of the Resilience Builder Program $\otimes(R B P)$, a manualized, 12-week resilience-based group therapy program, for children with HFASD within a clinical service setting. RBP addresses social competence deficits by targeting skills such as emotion regulation, resilience and social problem solving.
\end{abstract}

Methods: Data was collected from children ages 7-12 years who presented at a large private practice for treatment. Our sample was comprised of 17 children with HFASD $(12$ male; mean age $=11.04)$. Children were assessed on multiple domains of social, emotional, and behavioral functioning using measures given before beginning RBP and again after treatment ended.

Results: Findings revealed that parents endorsed significant improvement in their children's general social skills and in specific social domains such as responsibility, communication and engagement after participating in RBP. Children reported an increased ability to communicate with adults and endorsed less negative emotion as well as increased emotion control.

Conclusion: Results suggest that after undergoing the 12-week RBP group therapy, children with HFASD showed improvement in social skills, mood and emotion regulation. Despite aiming to treat heterogeneous social deficits, RBP successfully addressed core ASD social impairments. Results have important implications for expanded access to empirically-based treatments for HFASD youth in the clinical service settings in which they most frequently receive treatment.

Keywords: High-functioning autism; Social skills therapy; Group therapy; Social competence; Resilience; Clinical setting; Effectiveness

\section{Introduction}

With the rising prevalence of Autism in the United States, the mental health field has placed increasing emphasis on the development and implementation of interventions to address the core deficits of youth with Autism Spectrum Disorders (ASD) (Centers for Disease Control and Prevention, 2008). The primary features of Autism include impairment in social interaction, communication and restricted interests (DSM-IV, American Psychiatric Association, 2000). Although deficits in each of these three domains translate to pronounced functional impairment for these youth, impaired social functioning has been demonstrated to be the most persistent and permeating challenge throughout development, Social competence is the area of greatest vulnerability for youth with ASD regardless of their cognitive capacity $[1,2]$.

In one of the earliest descriptions of social impairment in Autism, Wing and Gould (1979) identified lack of social-emotional reciprocity as the overarching deficiency in ASD youth's social interactions. Lack of reciprocity can be further collapsed into the categories of social aloofness, impairment in social pragmatics, failure to attend to and respond to others' emotional, verbal and nonverbal cues as well as difficulties initiating and maintaining social interactions [3-5]. Given that reciprocity and mutuality are defining features of social relationships, individuals with Autism experience difficulty with socialization processes, which comes with both direct and indirect consequences for their quality of life. First and foremost, due to their social deficits, youth with Autism may not benefit from the supportive, emotional and affective functions of interpersonal relationships [6]. In addition, social competence deficits place children with ASD at an increased risk for social isolation, peer rejection and victimization [7]. Failure to enact appropriate social skills limits the opportunities in which these individuals can engage in positive social interactions. Consequently, youth with ASD report low levels of perceived social support and increased levels of social-cognitive loneliness [8]. Importantly, youth with High-Functioning ASD (HFASD), express a desire for greater social integration. This in turn suggests that in more cognitively able individuals with Autism, social functioning impairments may stem from a limited understanding of social situations versus an inability to experience affective ties towards others or social insensitivity $[8,9]$. Social cognition skill knowledge and implementation deficits may therefore be at the root of HFASD youth's impaired social functioning.

*Corresponding author: Dr. Brendan A. Rich, Ph.D. Department of Psychology The Catholic University of America 620 Michigan Ave, NE Washington, DC 20064 USA, Tel: 202-319-5823; Fax: 202-319-6263; E-mail: richb@cua.edu

Received July 25, 2013; Accepted May 12, 2014; Published May 20, 2014

Citation: Aduen PA, Rich BA, Sanchez L, O'Brien K, Alvord MK (2014) Resilience Builder Program Therapy Addresses Core Social Deficits and Emotion Dysregulation in Youth with High-Functioning Autism Spectrum Disorder. J Psychol Abnorm Child 3: 118. doi:10.4172/2329-9525.1000118

Copyright: ( 2014 Aduen PA, et al. This is an open-access article distributed under the terms of the Creative Commons Attribution License, which permits unrestricted use, distribution, and reproduction in any medium, provided the original author and source are credited. 
Social cognition encompasses emotion recognition abilities, and attention towards and prioritization of social stimuli and theory of mind [10]. Further study has validated the notion that social deficits in youth with HFASD are not predominantly explained by a lack of social interest suggest that social competence difficulties in HFASD youth emerge from a lack of social cognition skill knowledge coupled with diminished ability to determine when social skills should be implemented. Taken together, this evidence supporting social cognition skill knowledge and performance deficits in ASD implies that explicit training of social skills in a group format is a valuable and suitable intervention for children with HFASD. Given the permeating nature of social deficits, this specific type of intervention has the potential to induce cascading positive outcomes for this population [11].

Increasing interest in remediating social impairments in youth with Autism has been paralleled by a steady progression of the development and implementation of social skills group training interventions [12]. As knowledge about the nature of these impairments has furthered, interventions aimed to teach the social skills and pragmatics necessary for social competence have emerged as the preferred treatment for social deficits in HFASD youth [13]. Didactic instruction, behavioral practice, including modeling and role-playing, and generalization are core, systematic elements of social skills training [14]. This type of intervention may be particularly suited for this population as the course of treatment often involves breaking down complex social tasks into manageable, feasible components. Furthermore, the group therapy context is a unique setting for social skills training as it allows children to practice the learned skills with their peers in a facilitated, structured group environment with feedback from both the therapist and their peers [15]. The ultimate goal of this therapeutic approach is that the social skills learned and practiced in the intervention will generalize to the child's naturalistic social milieu.

Research examining the efficacy of manualized social skills intervention programs remains limited and has predominantly studied treatment outcome in academic research settings. Moreover, conclusions regarding the efficacy of group based social skills interventions have been mixed and demonstrate that empirical support for this type of intervention for youth with HFASD is in its infancy [16]. Meta-analytic reviews have found generally positive outcomes associated with group based social interventions for HFASD youth, albeit with inconsistencies, weak effects and evidence of poor maintenance of skills $[2,11,16]$. Notwithstanding, group based social skills interventions rooted in cognitive behavioral approaches may be amongst the most efficacious for this population $[7,13,17]$.

A limited number of studies have examined the effectiveness of cognitive behavioral, group-based, social skills training interventions in the research setting. This group of studies can best be categorized by intensity, therefore yielding two clear groups: interventions lasting 10 weeks or less and interventions lasting more than 10 weeks [13]. Regardless of the interventions' duration and intensity, generally these social skills groups adhere to a skill streaming protocol which involves Cognitive Behavioral Therapy (CBT) based instruction, modeling, role play, feedback and a homework component $[18,19]$. The intervention has a predictable and consistent course, typically beginning with a module dedicated to teaching social skills and pragmatics and ending with a module focused on skill enactment, reinforcement and generalization. Sessions are also highly structured, not only regarding the topics to be taught and learned in each session but also regarding the steps to skills achievement.

Across therapeutic interventions lasting 10 weeks or less, studies have found that group-based, social skills training improved HFASD youth's general social skills, and increased social knowledge and understanding of social pragmatics, according to parent report, Importantly, however, improvement was not consistent as interventions failed to increase. HFASD youth's self-reported emotion recognition and understanding [14,18-20]. A 10-week group-based, social skills training also failed to improve social skills in HFASD youth with comorbid Attention-Deficit/Hyperactivity Disorder (ADHD) [14]. Evidence of improved social cognition and social skills has been more consistent across interventions lasting longer than 10 weeks. Children and adolescents who completed a 7-month intervention focused on social skill instruction, affective education and social problem solving were reported to improve in social skills, emotion recognition and awareness and also showed an increase in social initiating behaviors [10,21-23]. Cumulative gains in social competency appear to be prevalent in youth with HFASD who enroll in interventions of longer duration and intensity.

Despite promising evidence from efficacy studies examining interventions of both short and long durations, the majority of research has been conducted in the academic research context without validation in the clinical service setting. Treatments found to be efficacious in the academic research context do not necessarily translate to be effective in the outpatient settings [24]. This may reflect differences in resources available to the clinic, training and experience of clinicians, and heterogeneity of clientele $[25,26]$. This means that although HFASD youth are typically referred to clinical service settings for group social skills training, the field virtually lacks evidence that group SSTs are effective in the therapeutic settings where most HFASD youth are treated $[15,27]$.

To our knowledge, only one study has been conducted examining the efficacy of a cognitive behavioral, group-based, social skills training intervention for school-aged children with HFASD in the clinical service setting. DeRosier and colleagues examined the effectiveness of the Social Skills Group Intervention-High Functioning Autism (S.S. GRIN-HFA), a 15-week social skills intervention for HFA youth ages 8 to 12 , in the context of a private, community based practice. The intervention is divided into three modules emphasizing effective communication, working with others and relational skills through didactic instruction and active practice of skills both outside and within session. Each module is comprised of 5 sessions that elaborate upon the module theme. After their children completed S.S. GRIN-HFA, parents reported improvement in general social skills and related subdomains such as communication, motivation, awareness and mannerisms. However, children did not report reduced feelings of loneliness or an improved sense of self-efficacy. In addition, this study was limited by a lack of teacher reported data. Therefore, the extent to which children's social skill improvements generalized to other contexts remains unclear [28].

In sum, there exists an alarming gap between the rate at which youth with HFASD are receiving group social skills training in clinical settings, and empirical evidence that these interventions are in fact effective with this population and in this setting. The present study aims to contribute to bridging the science to practice gap by examining the effectiveness of a resilience-based, CBT group therapy, the Resilience Builder Program ${ }^{\circ}$ (RBP), in improving HFASD youth's social and emotional functioning. RBP expands beyond traditional group social skills training to more broadly address resilience-skills. Resilience is broadly defined as positive adaptation to challenging life stressors. Notably, social relationships have been identified as a fundamental source of resilience. Therefore improving social functioning in children who struggle with developmental disabilities can serve as a protective 
Citation: Aduen PA, Rich BA, Sanchez L, O'Brien K, Alvord MK (2014) Resilience Builder Program Therapy Addresses Core Social Deficits and Emotion Dysregulation in Youth with High-Functioning Autism Spectrum Disorder. J Psychol Abnorm Child 3: 118. doi:10.4172/23299525.1000118

Page 3 of 10

factor for everyday life challenges that they may encounter. RBP undertakes this task and aims to advance social competence by means of a structured, 12-week intervention that emphasizes resilience-based skills, including heterogeneous social competence deficits, emotion regulation, adaptability and flexibility, as well as proactive social problem solving. We predicted that this group-based, CBT intervention would improve social and emotional functioning in HFASD youth through its focus on resilience-based skills. Additionally, we hypothesized that RBP treatment would significantly reduce behavioral symptomology in HFASD youth and result in improved family functioning $[29,30]$.

\section{Methods}

\section{Participants}

A total of 102 families enrolled in the Resilience Builder Program (RBP) group therapy program and of these 86 families agreed to participate in the study. Consent was obtained from the parent and assent was obtained from the children in these families, for an enrollment rate of $84.3 \%$. Of this larger sample, 17 children were identified by their parent as having a diagnosis of an Autism Spectrum Disorder and comprised the present study's sample. This sample was comprised of 12 males and 5 females with mean age of 10.35 years $(\mathrm{SD}=1.27)$. Of this participant sample, $82.4 \%$ were Caucasian and $76.5 \%$ of the families reported income above $\$ 100,000$. Comorbidity was prevalent among this sample, with ADHD being the most common co-occurring disorder $(58.8 \%)$. Other comorbid diagnoses included Generalized Anxiety Disorder (GAD) (29.4\%), Learning Disorder (LD) (29.4\%), Obsessive Compulsive Disorder (OCD) (11.8\%) and Oppositional Defiant Disorder (ODD) (5.9\%). Within this sample, $64.7 \%$ of children were currently taking medication. Notably, there was a significant overlap between children who were currently on medication and those with a co-occurring diagnosis of ADHD. See Table 1 for detailed demographic and clinical data.

\begin{tabular}{|c|c|c|}
\hline \multicolumn{1}{|c|}{ Variable } & $\mathbf{n}$ & $\%$ \\
\hline Ethnicity & & \\
\hline Caucasian & 14 & 82.4 \\
\hline African American & 1 & 5.9 \\
\hline Asian & 1 & 5.9 \\
\hline Biracial & 1 & 5.9 \\
\hline Gender & & 70.6 \\
\hline Male & 12 & 29.4 \\
\hline Female & 5 & 76.5 \\
\hline SES & 13 & 17.6 \\
\hline Over 100K & 3 & 5.9 \\
\hline \$75-100K & 1 & 41.2 \\
\hline \$50-74K & & 29.4 \\
\hline Diagnosis & 7 & 5.9 \\
\hline ADHD & 5 & 29.4 \\
\hline GAD & 1 & 11.8 \\
\hline ODD & 5 & 64.7 \\
\hline LD & 2 & \\
\hline OCD & 6 & \\
\hline Any anxiety & & \\
\hline Currently on Medication & & \\
\hline AD: Atention-Defict/HpAD: & \\
\hline
\end{tabular}

ADHD: Attention-Deficit/Hyperactivity Disorder; GAD: Generalized Anxiety Disorder; ODD: Oppositional Defiant Disorder; LD: Learning Disorder; OCD: Obsessive Compulsive Disorder

Table 1: Demographic and Clinical Variables.

\section{Procedure}

The participants of this study were a subset of a larger sample of participants who enrolled and presented for treatment at a large private psychotherapy practice located in Rockville and Silver Spring, Maryland. These participants were part of a larger study aimed at exploring the effectiveness of RBP in addressing heterogeneous social skill deficits across various childhood disorders. The practice where the intervention was implemented provides mental health services in both the individual and group format for children and adolescents presenting with various types of psychopathology. The practice treats over 300 children each year in group therapy, making it perhaps the largest provider of group psychotherapy to children in a private clinical setting in the United States.

Individuals were determined to be eligible for enrollment in RBP and inclusion in the study through a clinical intake assessment with a licensed clinician of the practice. Individuals in the current sample were those whose deficits would be consistent with high-functioning autism and/or Asperger's Disorder. Exclusionary criteria included a clinical diagnosis of Conduct Disorder and/or significant behavioral difficulties, as well as symptoms of psychosis, as the intervention is not appropriate for this degree of impairment. During the intake assessment, families were introduced to the research purposes and were asked to indicate if they wished to be contacted regarding participation. Graduate and undergraduate research assistants from the Catholic University of America later contacted the families who expressed interest in participation via telephone to explain the study and review consent and assent forms with the parent and the child. In-person consent and assent were then obtained at the first therapy session.

Pre-therapy data was collected from parents and children no more than two weeks prior to or after the first RBP session in order to obtain an accurate measure of baseline functioning. Post-therapy data was similarly collected from parents and children no more than two weeks after the end of the 12-week intervention. Of the 17 participants, $100 \%$ completed pre-and-post therapy data on the primary outcome measures of interest: the Social Skills Improvement System-Rating Scales (SSIS-RS; and the How I Feel Scale).

\section{Intervention}

Participants enrolled in the Resilience Builder Program; a manualized group psychotherapy intervention. Each therapist-led group session is held for one hour, once a week, over a 12-week time span and is comprised of four to six same sex and similar-aged children. RBP aims to address social competence deficits primarily having to do with difficulty integrating behavioral, cognitive, and affective skills in social contexts. Because this intervention aims to target heterogeneous social skills deficits rather than social deficits specific to one disorder, children who enroll in RBP present with a range of disorders including ASD, ADHD and anxiety. RBP overlaps with many standard CBT techniques. For example, RBP interventions focus on the youth's cognitive distortions. These may include ways in which children misinterpret social situations and the faulty thoughts that contribute to inaccurate understanding of peer interactions or their own emotional or behavioral problems. As an example, the clinician may use a magnetic dartboard to demonstrate "on the mark" versus "off the mark" thinking about accurate vs. inaccurate thoughts. Like traditional CBT approaches, RBP focuses on identifying behavioral deficits, such as problematic social skills (i.e., self-focused conversations, failure to maintain eye contact, inappropriate personal space) or dysregulated behavior (i.e., being overly aggressive, destructive behaviors when frustrated). To address these, RBP follows common CBT techniques 
including role-plays where youth get to practice new skills in mock social scenarios. RBP also focuses on self-regulation via traditional $\mathrm{CBT}$ relaxation techniques, such a deep breathing (i.e., diaphragmatic breathing), progressive muscle relaxation, and self-talk [31].

At the same time, a particular strength of RBP is that is goes beyond traditional CBT and group social skill training approaches to target resilience-based skills. At its core, RBP is a strength-centered treatment that focuses on protective factors designed to build resilience skills and promote social competence organized the protective factors into six broad areas: 1 ) a proactive orientation toward life; 2 ) the ability to regulate one's attention, emotions, and behavior for improved selfcontrol; 3) social connections and attachments; 4) development and acknowledgment of special talents; 5) a strong community; and 6) proactive parenting. As an example, sessions that target being proactive teach youth to take the initiative and create preemptive plans for dealing with social situations and interactions with peers, rather than being reactive or passive. Similarly, RBP teaches youth how to be flexible and adapt to stressors and social challenges. Another unique focus is developing in youth an ability to actively engage in community activities, in part by identifying the youth's strength and interests that will foster social success. RBP's focus on building social-competence skills within a resilience-building framework may best promote comprehensive improvement in psychosocial functioning [30,31].

The typical framework of an RBP session consists of three-principle components: an Interactive Didactic Component (duration of 30 minutes), a Free Play/Behavioral Rehearsal Component (duration of 20 minutes), and a Relaxation/Self-Regulation Component (duration of 10 minutes). The session begins with the Interactive Didactic component in which the therapist and children actively review homework tasks and discuss advancement towards individual goals. During this component, the social and resilience skills that will be target in session are outlined and demonstrated by the therapist. Children are asked to actively engage in the understanding of this skill by thinking about the skill of the day and putting forth their own ideas about the behaviors involved in enacting the specific skill. To ensure that the group has mastered the concept well, occasionally role-play is incorporated in the Didactic Component, which gives children the opportunity to enact the skill in a safe environment and to learn how the skill is carried out successfully in social contexts. Examples of role-plays include the creation of mock social situations, such as approaching a peer on the playground, starting a conversation with a peer, or engaging in conversation without interrupting. The second component of RBP, Free Play/Behavioral Rehearsal, involves children practicing the target skill introduced in the Didactic Component through real-life play situations with others in the group. Children engage in activities or games in which they must put cooperation and negotiation social skills into practice in order to carry out the group activity successfully. They also practice the skills and behaviors learned during the first part of the session, which enables them to effectively interact with the other children. While the children engage in these group activities, the therapist monitors their social behavior by providing corrective feedback or positive reinforcement to each individual child's behavioral progress. There is great value in the free-play portion of the session as it provides children the opportunity to rehearse the taught skills. It is also an opportunity for children to model their peers' appropriate social behavior while providing and receiving feedback from both other children in the group and the therapist.

The last component of each session inculcates Relaxation and SelfRegulation techniques such as progressive relaxation, visualization, and positive self-talk, along with other emotional and behavioral regulation strategies. The therapist introduces these techniques so that the group as a whole can practice implementing them.

RBP places a strong emphasis on the generalization of the skills learned in therapy sessions to contexts and scenarios of the child's life outside of treatment. The intervention provides multiple opportunities for children to practice these learned skills, such as the weekly "Resilience Builder" homework assignments. These assignments ask children to provide examples of how he or she was able to apply RBP skills at home and at school during the week. In addition to these homework assignments, children are asked to complete a weekly "Success Journal" where the children are asked to provide examples of successful attempts related to attainment of their individual goals. At the beginning of each session, children then read aloud their "Success Journal" entries to their group peers. An additional essential component of skill generalization in RBP is participation in a group field trip, where the therapist takes the group to a public setting for an activity such as mini-golf. In this new, public setting, children are able to practice the skills that they have learned in earlier sessions of the intervention.

The parental component of RBP allows parents to be involved with the treatment and also receive feedback of their child's progress in the group. Weekly letters to parents provide them with updates on the skills that were taught in the session for their own information purposes and also so that they may help their children implement these learned skills out of therapy in real-world scenarios and via the weekly "Resilience Builder" homework assignments. Therapists also provide parents with instructions on how to provide appropriate positive feedback and reinforcement for the child's efforts and progress in mastering the learned skills. Furthermore, parents are offered the opportunity to join the final 20 minutes of a session once a month so that they may see the child's progress in the group.

Each RBP session theme pertains to critical skills that are integral to effective social interactions and interpersonal relationships. RBP session topics include Introduction; Resilience: Being Proactive; Personal Space; Leadership; Reading Cues: Verbal and Nonverbal; Initiating and Maintaining Conversations; Sportsmanship; Optimistic Thinking; Problem Solving; Stress Management; and Empathy. Below we provide an outline of the structure of RBP sessions:

Session 1 (Introduction): In the first session, children meet their fellow group members. The therapist introduces the children to the program, and establishes the ground rules for the sessions. In addition, the children are asked to begin identifying their individual semester goals through the first homework assignment.

Session 2 (Resilience: Being Proactive): Children learn the definition of "resilience" and its importance in daily skills. Through the use of role-play, children learn how to take initiative and to be flexible as well as the importance of being proactive versus reactive or passive.

Session 3 (Personal Space): Discussion, demonstration, and role-play aid children in learning how to maintain "personal space" by focusing on the physical distance between people and the subtle boundaries of personal space. Children learn the importance of space (i.e., speed of speech and movement) and tone/volume of voice when interacting with others.

Session 4 (Leadership): Children learn about the six components of being a good leader which include being proactive, communicating effectively, being flexible and adapting to other's needs, maintaining selfcontrol, being a good role model, and being a team player. Discussion amongst group members is used as a vehicle to generate examples of leader behaviors, as well as annoying behaviors. 
Citation: Aduen PA, Rich BA, Sanchez L, O'Brien K, Alvord MK (2014) Resilience Builder Program Therapy Addresses Core Social Deficits and Emotion Dysregulation in Youth with High-Functioning Autism Spectrum Disorder. J Psychol Abnorm Child 3: 118. doi:10.4172/23299525.1000118

Session 5 (Reading Verbal and Nonverbal Cues): Through the use of pictures, role-play, and video feedback, children learn how to interpret verbal and nonverbal cues that take place during peer interactions. In addition to learning how to decipher social verbal and nonverbal cues, children are also taught how to respond flexibly to these cues.

Session 6 (Initiating and Maintaining Conversations): Children learn about conversation "builders" which include maintaining ontopic conversations, asking appropriate questions, effective use of eye contact, and getting the other person's attention before asking a question. They are also taught the concept of conversation "busters", which include behaviors that will likely stop the interaction. These skills are practiced and reinforced through interactive activities used in session.

Session 7 (Good Sportsmanship): Children learn about the various skills that compose good sportsmanship including following rules, encouraging/complimenting others, controlling frustration and disappointment, adapting to changing demands of the game, and playing fair. These skills are practiced with the "Wii" game system with the aim to replicate an activity that the children would typically engage in in their home environment.

Session 8 (Optimistic Thinking): Children learn the difference between optimistic and pessimistic thinking while also learning how their thinking influences their feelings and actions. Children learn to identify their thoughts and are taught that they have control to change or "replace" their maladaptive thoughts with other more adaptive thinking. The concept of "changing the channel" on thoughts is introduced.

Session 9 (Problem Solving): Children are taught to conceptualize problems as challenges to be overcome and to approach these challenges in a proactive and flexible way. Children practice problem solving and identifying options to improve their mental flexibility and coping in response to life stressors.

Session 10 (Stress Management): Children learn about stress management, self-regulation and other skills to manage daily stress. In addition, children are taught to develop plans for coping strategies.

Session 11 (Generalization Field Trip): Children are given the opportunity to practice the skills they have been taught and to strengthen their social and self-regulation skills in real-world settings, such as playing mini-golf or going bowling. Children practice positive interactions and regulating their behavior with adults in these community settings.

Session 12 (Empathy and Perspective-Taking and Review of Sessions): In the final session, children learn about empathy and discuss examples of how others might feel or think given a particular scenario. Towards the end of session, the children practice speaking to a group as they present what they have learned over the semester to their group members and their parents.

\section{Measures}

To assess treatment outcome, a parent, the child, and a teacher were asked to complete a battery of standard psychological rating scales assessing a range of domains both before and after the completion of RBP treatment.

The Behavior Assessment System for Children (BASC-2) [32] is a widely used broadband measure of child social, emotional, and behavioral functioning. Parents, children, and teachers respond to items on a 4-point Likert scale ranging from Never to Almost Always.
The BASC-2 assesses domains including Internalizing functioning, which encompasses scales such as Depression and Anxiety, and Externalizing functioning, which includes scales such as Hyperactivity and Conduct Problems. The BASC-2 includes highly salient subscales that pertain to the present study's focus including Resiliency, Emotional Self-Control, Negative Emotionality, Anger Control, and Social Skills. The latter domains are highly pertinent to RBP and facilitate outcome measurement in examining the efficacy of this intervention. The BASC2 has demonstrated sound psychometric properties [32].

Social Skills Improvement System- Rating Scales (SSIS-RS) [33]: The SSIS-RS is a 75-item measure that assesses a child's social skills and problem behaviors. Children rate how accurately the statements reflect their behavior, while parents and teachers rate how often the behavior has occurred in the previous two months on a 4-point Likert scale ranging from Never to Almost Always. Examples of subscales include Communication ("Speaks in appropriate tone of voice"), Cooperation ("Takes turns in conversations"), Assertion ("Stands up for those who are treated unfairly"), Responsibility ("Takes care when using other people's things and increased ability to communicate with adults"), Empathy ("Tries to make others feel better"), Engagement ("Interacts well with other children"), and Self-Control ("Takes criticism without getting upset"). The SSIS-RS is considered by some to be the gold standard for social skills measures due to its comprehensive approach. Results can be applied broadly, given that it assesses social skills across various reporters and has strong psychometric properties [34].

How I Feel (HIF) [35]: The HIF obtains child self-reported ratings of positive and negative emotionality as well as emotion control. This measure includes 30 items that ask children to rate the frequency with which they have experienced different emotions over the past 3 months on a 5-point Likert scale ranging from Not at all true of me to Very true of me. The HIF has demonstrated good test-retest reliability, as well as content and convergent validity [35].

Family Assessment Device (FAD) [36] Parental ratings of family functioning were obtained using the FAD, which is a 60 -item measure that assesses six dimensions of family dynamics, including Problem Solving, Communication, Roles, Affective Responsiveness, Affective Involvement, Behavior Control, and General Functioning. Parents rate items on a 4-point Likert scale ranging from Strongly Agree to Strongly Disagree. The FAD has been shown to be psychometrically sound, with established cut-off and normative scores [37].

Demographic Form: Parents completed a demographic form whereby supplemental clinical information was gathered including the child's age, gender, ethnicity, family SES, number of siblings, current and past psychological diagnoses, and current and past psychotherapeutic and psychopharmacological treatment. This measure included questions pertaining to the child's functioning in "real world" social situations (e.g., number of close friends, play date invitations, participation in after school and extracurricular organizations, etc.). Whereas most standardized measures assess a child's social skills, these questions were included in an effort to obtain a more ecologically valid measure of the frequency and quality of peer and social interactions.

\section{Analyses}

Children's pre- and post-therapy functioning was compared using paired-sample t-tests and chi-square analyses across BASC-2, SSIS, HIF, and FAD scores as the dependent variables. Given the exploratory nature of this pilot study and small sample size which limited power, a statistical procedure was not employed to adjust for Type I error rate as it might overly restrict the ability to detect changes in functioning following intervention. 
Citation: Aduen PA, Rich BA, Sanchez L, O'Brien K, Alvord MK (2014) Resilience Builder Program Therapy Addresses Core Social Deficits and Emotion Dysregulation in Youth with High-Functioning Autism Spectrum Disorder. J Psychol Abnorm Child 3: 118. doi:10.4172/23299525.1000118

Page 6 of 10

\section{Results}

We report only significant results based on parent, child, and teacher report (Tables 2 and 3). We note that significant changes were not found in pre- versus post-therapy functioning on either the BASC-2 or the FAD measures.

\section{Parent report}

On the SSIS, findings indicated that parents endorsed improvement in their children's general social skills, indicative of increased positive interactions in appropriate social settings, after their participation in RBP. Parents reported that their children had significantly higher levels

\begin{tabular}{|c|r|r|r|r|r|}
\hline Variable & \multicolumn{2}{|r|}{ Pre-Treatment } & Post-Treatment & p-value \\
\hline Social Functioning & M & SD & M & SD & \\
\hline Parent-Report & & & & & \\
\hline Social Skills & 78.67 & 9.79 & 88.00 & 7.18 & .03 \\
\hline Responsibility & 8.80 & 2.39 & 10.80 & 2.93 & .01 \\
\hline Emotional Functioning & & & & & \\
\hline Child-Report & & & & & \\
\hline Emotion Control & 26.88 & 9.79 & 32.50 & 9.71 & .05 \\
\hline Negative Emotion & 36.88 & 10.87 & 28.38 & 7.60 & .03 \\
\hline
\end{tabular}

Table 2: Domains of Functioning with Significant Change Following Treatment with the Resilience Builder Program ${ }^{\circledR}$.

\begin{tabular}{|c|c|c|c|c|c|c|c|}
\hline \multirow[b]{2}{*}{ Variable } & \multicolumn{3}{|c|}{ Pre-Treatment } & \multicolumn{3}{|c|}{ Post-Treatment } & \multirow[b]{2}{*}{ p-value } \\
\hline & $\begin{array}{c}\text { Below } \\
\text { Average }\end{array}$ & Average & $\begin{array}{c}\text { Above } \\
\text { Average }\end{array}$ & $\begin{array}{c}\text { Below } \\
\text { Average }\end{array}$ & Average & $\begin{array}{c}\text { Above } \\
\text { Average }\end{array}$ & \\
\hline \multicolumn{8}{|l|}{ Social Functioning } \\
\hline \multicolumn{8}{|l|}{ Parent-Report } \\
\hline Communication & $60 \%$ & $40 \%$ & & $20 \%$ & $80 \%$ & & 0.05 \\
\hline Engagement & $50 \%$ & $50 \%$ & & $30 \%$ & $70 \%$ & & 0.04 \\
\hline \multicolumn{8}{|l|}{ Child-Report } \\
\hline Responsibility & $37.5 \%$ & $62.5 \%$ & & $25 \%$ & $75 \%$ & & 0.04 \\
\hline \multicolumn{8}{|l|}{ Emotional Functioning } \\
\hline \multicolumn{8}{|l|}{ Parent-Report } \\
\hline Internalizing Prob. & $10 \%$ & $50 \%$ & $40 \%$ & & $50 \%$ & $50 \%$ & 0.01 \\
\hline
\end{tabular}

Table 3: Domains of Functioning with Significant Change Following Treatment with the Resilience Builder Program ${ }^{\circledR}$.

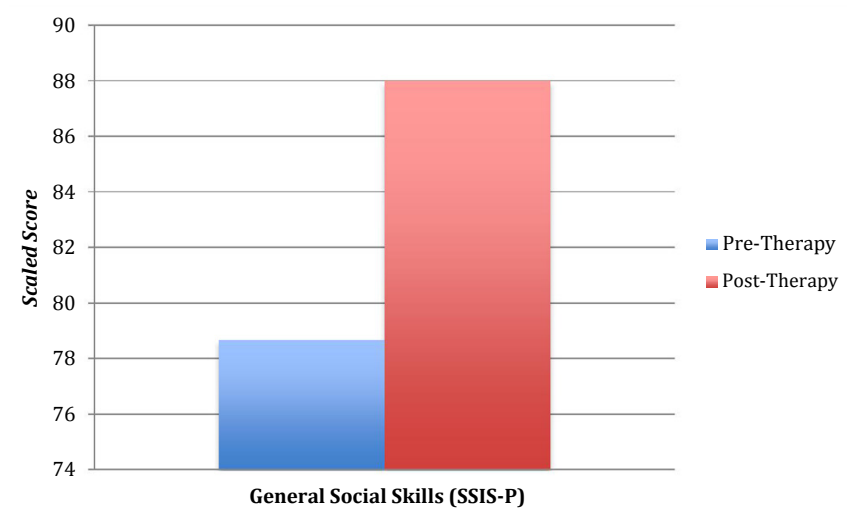

SSIS-P = Social Skills Improvement System- Parent Report Figure 1: Significant Improvement in Parent-Reported Social Functioning
Following Treatment with the Resilience Builder Program ${ }^{\circledR}$.

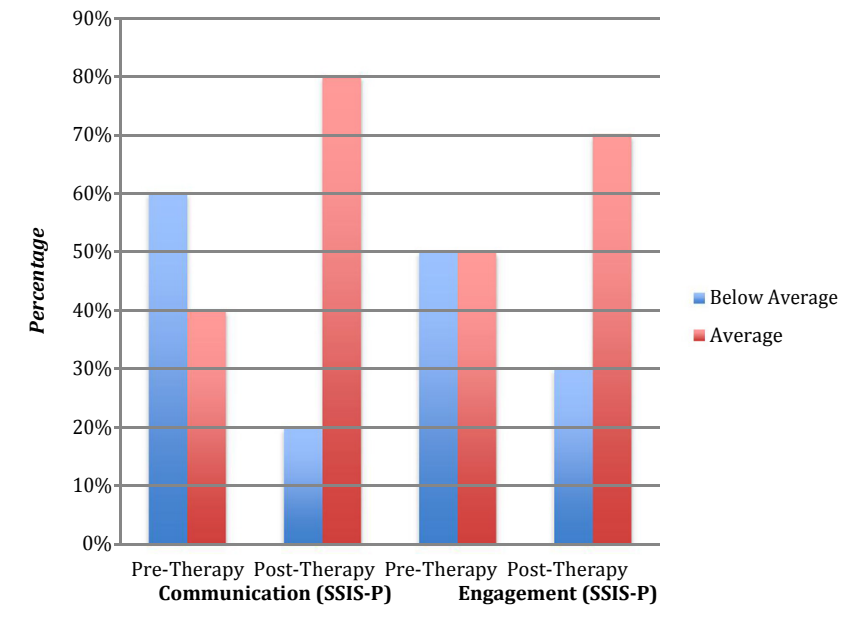

SSIS-P = Social Skills Improvement System- Parent Report

Figure 2: Significant Improvement in Parent-Reported Communication and Engagement Subdomains Following Treatment with the Resilience Builder Program ${ }^{\circledR}$.

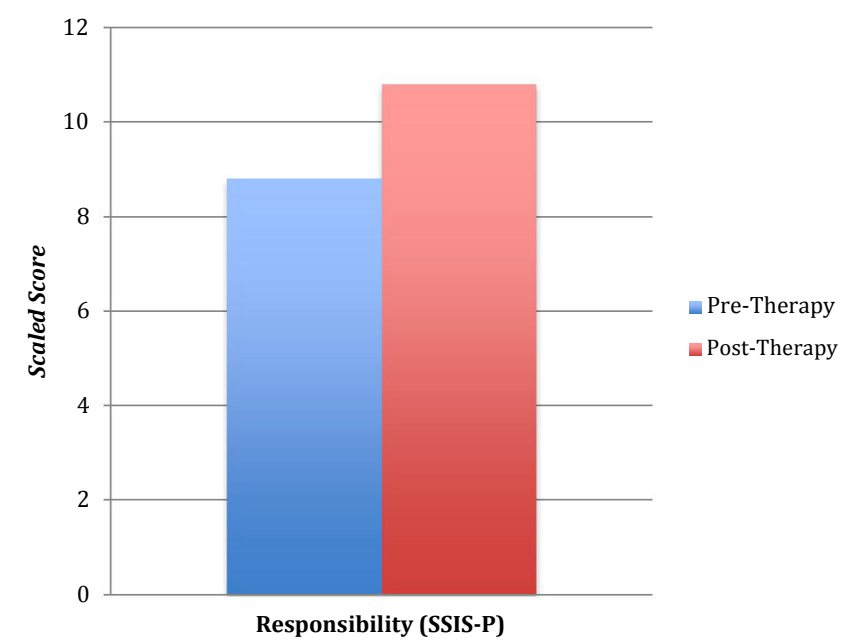

SSIS-P = Social Skills Improvement System- Parent Report

Figure 3: Significant Improvement in Parent-Reported Responsibility Subdomain Following Treatment with the Resilience Builder Program ${ }^{\circledR}$.

of adaptive Social Skills after undergoing RBP $(M=88.00, \pm 7.18)$ than before beginning the intervention $(\mathrm{M}=78.67, \pm=9.79),[\mathrm{t}(8)=-2.59$, $\mathrm{p}<.05]$ (Figure 1). Parent report also suggested significant improvement in specific subdomains of social skills (Figures 2 and 3). For example, parents endorsed child improvement in areas such as Communication $\left[\mathrm{X}^{2}(1)=3.75, \mathrm{p}<.05\right]$, implying an increase in adaptive, communicative behaviors and skills. Before beginning RBP, $60 \%$ of children found themselves below average on Communication skills while $40 \%$ of children were average. After undergoing the 12 -week intervention, only $20 \%$ of children were below average on Communication skills while $80 \%$ of children were average, indicating significant improvement in this domain. Furthermore, an increase in Engagement in participants' social behavior was reported by parents after RBP, suggesting an increased concern and initiative to interact with others, $\left[\mathrm{X}^{2}(1)=4.29\right.$, $\mathrm{p}<.05$ ]. While $50 \%$ of children found themselves with below average levels of Engagement and 50\% of children had average levels of Engagement before RBP was implemented, 30\% had reported below average levels and 70\% had reported average levels of Engagement after 
Citation: Aduen PA, Rich BA, Sanchez L, O'Brien K, Alvord MK (2014) Resilience Builder Program Therapy Addresses Core Social Deficits and Emotion Dysregulation in Youth with High-Functioning Autism Spectrum Disorder. J Psychol Abnorm Child 3: 118. doi:10.4172/23299525.1000118

Page 7 of 10

the intervention. Participants' improvement was also reported in the subdomains of Responsibility, indicating that parents perceived that their children were better able to communicate with adults and show regard for their property after the social skills training intervention $(\mathrm{M}=10.80 \pm 2.75)$ compared to levels of Responsibility before beginning $\operatorname{RBP}(\mathrm{M}=8.80 \pm 2.39),[\mathrm{t}(9)=-3.25, \mathrm{p}<.01]$

Although parents endorsed improved social functioning following $\mathrm{RBP}$, their report also indicated an increase in Internalizing Problems on the SSIS $\left(\mathrm{X}^{2}(2)=10.00, \mathrm{p}<.01\right)$ (Figure 4$)$. Before beginning the intervention, $10 \%$ of children had parent-reported below average levels of internalizing symptoms, $50 \%$ found themselves at average levels and $40 \%$ were above average. After undergoing RBP, $50 \%$ of children had parent-reported average levels of internalizing disorder while $50 \%$ had above average levels.

\section{Child self-report}

As measured by the SSIS self-report, children endorsed improvement on the Responsibility domain of social skills, indicating an increased ability to communicate with adults after $\mathrm{RBP}\left[\mathrm{X}^{2}(1)=4.44\right.$, $\mathrm{p}<.01$ ] (Figure 5). Before undergoing the intervention, 37.5\% of children were at below average levels of Responsibility and $62.5 \%$ had average levels. After RBP, $25 \%$ of children were reported to be at below average levels of Responsibility while $75 \%$ were reported to be average.

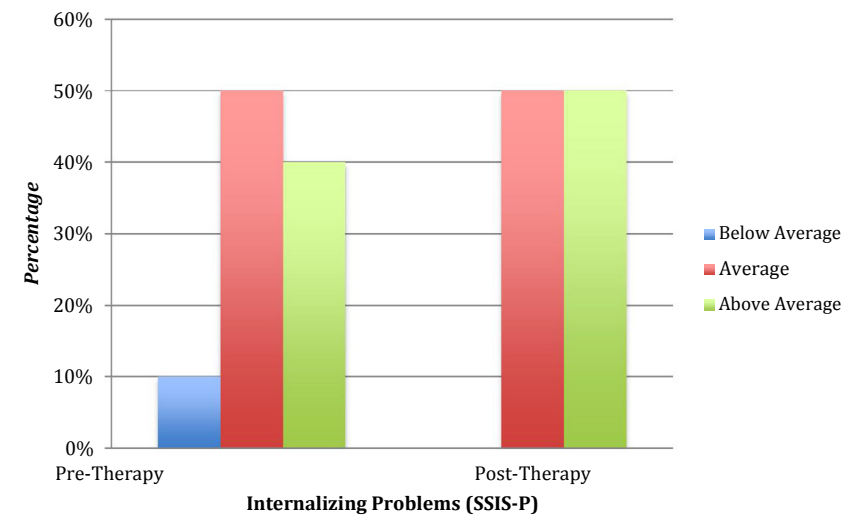

SSIS-P = Social Skills Improvement System- Parent Report

Figure 4: Significant Change in Parent-Reported Internalizing Problems Following Treatment with the Resilience Builder Program ${ }^{\circledR}$.

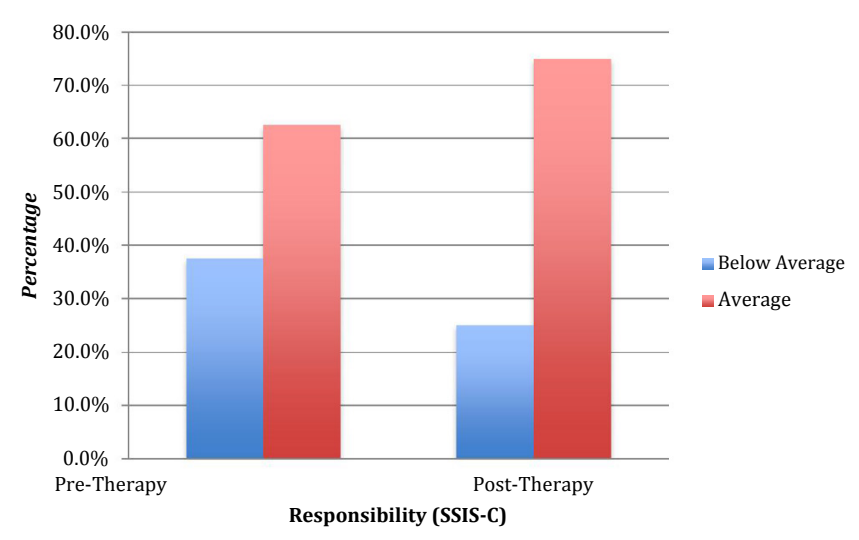

SSIS-C = Social Skills Improvement System- Child Report

Figure 5: Significant Improvement in Child-Reported Social Skills Subdomains Following Treatment with the Resilience Builder Program $®$.

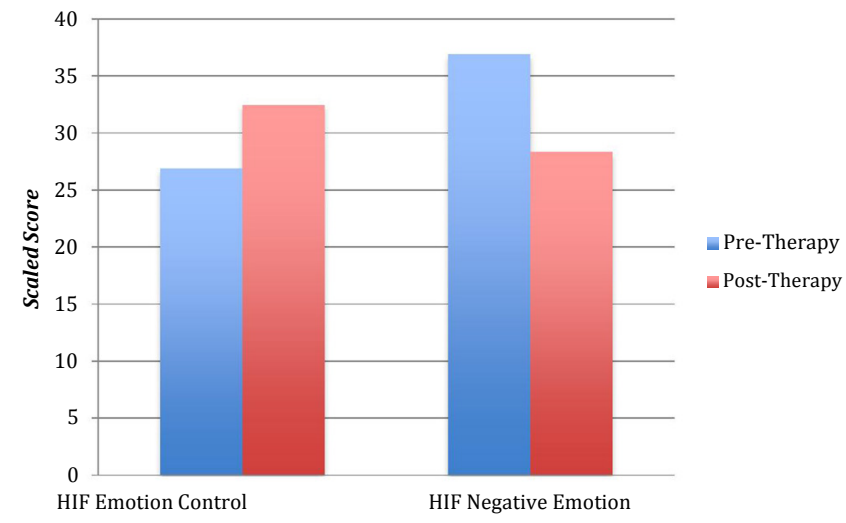

$\mathrm{HIF}=$ How I Feel Questionnaire

Figure 6: Significant Improvement in Child-Reported Emotional Functioning Following Treatment with the Resilience Builder Program ${ }^{\circledR}$.

In the emotionality domain, on average, HIF data indicated that participants experienced significantly greater emotion control after undergoing the intervention $(\mathrm{M}=32.50 \pm 9.71)$ compared to levels of emotion control before beginning RBP $(\mathrm{M}=26.88, \mathrm{SD}=9.79)$, $[\mathrm{t}(7)=$ $2.34, \mathrm{p}<.05]$. Additionally, children endorsed experiencing less negative emotionality after undergoing the RBP intervention $(28.38 \pm 7.60)$ compared to before the intervention $(\mathrm{M}=36.88 \pm 10.87),[\mathrm{t}(7)=2.80$, $\mathrm{p}<.03]$. See Figure 6 for results.

\section{Teacher report}

Significant changes in teacher-reported social skills were not found.

\section{Discussion}

The increasing rates of Autism in youth have catalyzed research efforts to both develop and test the effectiveness of interventions that address core deficits of the disorder. Social competence is notably the most permeating and pervasive impairment for HFASD youth consequently, interventions have been developed specifically to target these deficits with the aim to reduce negative outcomes for these individuals through improved social functioning. Although the number is growing, a limited number of group-based, CBT interventions have been developed to address social skills deficits in HFASD youth and fewer have been examined for their effectiveness [1]. With the exception of one study by Smith-Boydston and Nelson all studies have been conducted in the academic research setting without validation in the clinical, outpatient context [25]. Findings from these effectiveness studies have been generally promising in demonstrating improved social function in HFASD youth who undergo these interventions, although results are inconsistent $[14,16,18,21]$. Conclusions regarding improved emotionality in children who participate in these interventions are more inconclusive $[20,28]$. The present study contributes to this research base by examining the effectiveness of RBP, a resilience-based, CBT group intervention targeting heterogeneous social deficits, in improving social and emotional functioning in HFASD youth within a clinical service setting. Overall, RBP succeeded in improving social skills and emotionality in the HFASD youth that comprised this study's sample. Conversely, significant changes brought about by RBP participation were not found in children's behavioral symptomology or family functioning. The implications of these findings are discussed in turn.

Following completion of the 12-week intervention, parents reported improvement in their children's broad, adaptive social skills. These findings are consistent with past studies that have provided 
evidence for improved general social skills in HFASD youth after undergoing a group-based, social skills training intervention $[18,20,28]$ In our study, parents also reported improvement in specific domains of social skills including communication, responsibility and engagement. Improvement in communication speaks to the appropriate use of social pragmatics, such as making eye contact, taking turns when speaking with other individuals and the proper use of manners in social contexts. These fundamental skills are taught in the beginning sessions of RBP and reinforced throughout the course of treatment as children interact with not only their peers but also the therapist, thereby promoting generalization to all contexts and persons. The present study replicates prior findings that have suggested that group-based social skills training interventions improve HFASD youth's communication skills [20,28]. Improved communication and social pragmatic skills are particularly remarkable findings, as these skills are a central aspect of impairment in youth with Autism [9].

A parent-reported improvement in responsibility is related to improved communication, as responsibility encompasses proficiency in communicating with adults in addition to being mindful of one's and others' property. Children also reported positive development in the domain of responsibility. Parent and child agreement regarding gains made in this domain may be suggestive of an improved communicative relationship between parents and children. If these children are better able to communicate with others, the give and take of information in social contexts such as home and school will be understood more clearly. Specific improvements in the social skills domain of responsibility is a novel finding introduced by the present study to the social skills intervention and HFASD literature. Improved responsibility attests to the generalization of behavior as a result of training of specific skills, such as communication.

Lastly, parents reported that their children were more engaged in social interactions after undergoing RBP treatment. Increased motivation for social interaction as a result of group-based social skills interventions is a ubiquitous finding and perhaps one of the most important therapeutic goals of this treatment modality $[8,11,28]$. The present study's findings suggest that behaviors such as initiating and joining activities with others increased as a result of the RBP therapy. Improved social interactions with others are likely to have been a product of the group-based approach inherent to RBP, as instructed skills were consistently practiced in a social context through activities and games.

A surprising finding of the present study was a parent-reported increase in HFASD youth's internalizing problems (i.e., feelings of anxiety and sadness) after completing the intervention. In prior pilot studies of RBP, we did not find such increases in internalizing problems in youth with ADHD nor anxiety. One hypothesized cause of this finding is that throughout the course of treatment, due to the groupbased nature of RBP, HFASD children became more aware of their social deficits in comparison to their peers in the group. In support of this notion White \& Roberson Nay (2009), suggest that higher functioning youth with autism may experience heightened anxiety as a result of constant awareness of their misinterpretation of social cues and expectation of social failure. Moreover, it is important to note that the majority of children who comprise these RBP groups have a diagnosis of Anxiety or ADHD. Therefore, within these groups there is great variation in the nature and manifestation of social deficits as well as in the degree to which social functioning is impaired. The heterogeneity of these groups may have had an impact on the HFASD participants, whereby social comparison led to increased awareness of HFASD youth's social deficits, therefore increasing feelings of anxiety or sadness [39-41].
A second hypothesized explanation for a parent-reported increase in HFASD youth's internalizing problems is grounded in the fact that RBP intervention does not target mood issues specifically. It is possible that failure to incorporate mood issues as they relate to social competence in the RBP protocol could have resulted in this finding. Indeed, given that nearly $65 \%$ of the HFASD youth in this sample had an anxiety disorder, it is possible that increased parent-report of affective symptoms in part reflects the comorbid anxiety of our sample.

Further, although parents reported that internalizing symptoms increased following RBP, the children themselves reported the opposite: a significant decrease in negative emotionality and an increased ability to self-regulate their emotions. As previously mentioned, RBP intervention does not specifically target mood and emotionality throughout the course of treatment. However, it is likely that the resilience-based curriculum inculcated in every RBP session is related to increased levels of emotion regulation and less negative emotion. Skills such as proactive and adaptive problem solving teach children to better regulate their emotions and behavior in situations where reactivity would prevail. The intervention reinforces the use of these strategies to prevent maladaptive responses in various contexts of frustration or obstacles [30].

The present study failed to find significant results in anticipated domains of change including teacher-reported improvement of youth's social skills as well as changes in behavioral symptomology and family functioning. Lack of significant changes in these domains could have collectively resulted from the fact that RBP is not designed to target core symptomology of ASD. Although social deficits are the most pervasive symptom associated with HFASD, other core symptoms such as communication impairments and repetitive, stereotyped behaviors produce notable functional impairments in these individuals if they remained unaddressed. RBP successfully targeted social competence deficits in HFASD youth; however functioning could have remained impaired as a result of other core deficits. There is a possibility that teachers may have been perceptive to this continued impairment in behavior and therefore missed improvements in the children's social and emotional functioning. Furthermore, lack of behavioral change could also explain non-significant findings in family functioning.

In addition, the lack of significant change in the above domains could very well reflect a primary limitation of this study: our small sample size. This certainly limited our power to detect change, as well as our ability to conduct secondary analyses to examine the mechanisms of change following youth's participation in treatment. For example, it would be highly informative to examine the role of comorbid ADHD in response to RBP, but small sample size limited this type of analysis. An additional limitation is that this study's research design lacked a control group, making it challenging to conclude that improved functioning was due solely to RBP treatment. As our research moves forward, we are now collecting data from a waitlist, treatment-as-usual comparison sample. Another limitation to this study pertains to the use of parentreport in determining the HFASD diagnosis of youth in this sample. Although parent-reported diagnosis is a common resource used to determine clinical status, structured diagnostic measures did not verify the reliability of this diagnosis in this study. This reflects the challenges of conducting research in a private clinical setting, most notably the resources required to purchase assessment tools and train clinicians in their administration, the time required to conduct these structured interviews, and the financial ramifications to clients for receiving this assessment. Our reliance on parent report is consistent with other research conducted in a clinical setting. Finally, it is important to note that our analyses of outcome reflect within-group changes. That is, at 
Citation: Aduen PA, Rich BA, Sanchez L, O'Brien K, Alvord MK (2014) Resilience Builder Program Therapy Addresses Core Social Deficits and Emotion Dysregulation in Youth with High-Functioning Autism Spectrum Disorder. J Psychol Abnorm Child 3: 118. doi:10.4172/23299525.1000118

Page 9 of 10

this initial stage of study we do not have a comparison sample against which to compare RBP. We have now enrolled a treatment-as-usual waitlist control sample to better determine the extent to which changes in functioning reflect RBP itself $[41,42]$.

It is worthy to note that RBP targets heterogeneous social competency deficits across childhood psychological disorders, and is not tailored to the specific, core deficits of Autism. This, findings from the current study are promising as they revealed that RBP was effective in improving HFASD youth's social and emotional functioning.

Specifically, parents reported improved social functioning, especially within the domains of communication and engagement, while children reported better emotion regulation and less negative emotion after undergoing the intervention. This is only the second effectiveness study of psychotherapy in ASD youth conducted in the clinical setting and provides strong support for group-based, CBT social competency interventions as a way of remediating social deficits in HFASD individuals. Our hope is that results such as these may begin the process of dissemination of empirically-based treatments for HFASD youth in clinical service settings, thus expanding accessibility of these interventions to the settings where most HFASD youth are treated. In addition, given the effectiveness of this resilience-based curriculum with this population, it is critical that future research examine the specific mechanisms by which resilience improves social functioning within youth with Autism and incorporate resilience as a core feature in the development of social skills interventions for HFASD youth.

\section{Acknowledgement}

The authors wish to thank the families who participated in this study, as well as the clinicians and staff of the Alvord, Baker, \& Associates, LLC practice. This study was supported by Grant-in-Aid funds provided by the Catholic University of America.

\section{References}

1. Church C, Alisanski S, Amanullah S (2000) The social, behavioral, and academic experiences of children with Asperger Syndrome. Focus on Autism and Other Developmental Disabilities 15:12-20.

2. Reichow B, Volkmar FR (2010) Social skills interventions for individuals with autism: evaluation for evidence-based practices within a best evidence synthesis framework. J Autism Dev Disord 40: 149-166.

3. Dawson G, Faja S (2008) Autism Spectrum Disorders: A Developmental Perspective. In: Beauchaine TP, Hinshaw SP (Eds.), Child and Adolescent Psychopathology. John Wiley \& Sons, Inc, Hoboken, NJ, pp. 575-613.

4. Baron-Cohen S (1988) Social and pragmatic deficits in autism: cognitive or affective? J Autism Dev Disord 18: 379-402.

5. Kuusikko S, Haapsamo H, Jansson-Verkasalo E, Hurtig T, Mattila ML, et al (2009) Emotion recognition in children and adolescents with autism spectrum disorders. J Autism Dev Disord 39: 938-945.

6. Rubin KH, Coplan R, Chen X, Buskirk A, Wojslawowicz A (2005) Peer relationships in childhood. In: Bornstein MH, Lamb ME (Eds.), Developmental Science: An Advanced Textbook (5thedn), Lawrence Erlbaum, Mahwah, NJ, pp. 469-512.

7. Wang P, Spillane A (2009) Evidence-based social skills interventions for children with Autism: A meta-analysis. Education and Training in Developmental Disabilities 44: 318-342.

8. Bauminger N, Kasari C (2000) Loneliness and friendship in high-functioning children with autism. Child Dev 71: 447-456.

9. Baron-Cohen $S$ (1988) Social and pragmatic deficits in autism: cognitive or affective? J Autism Dev Disord 18: 379-402.

10. Bauminger N (2002) The facilitation of social-emotional understanding and social interaction in high-functioning children with autism: intervention outcomes. J Autism Dev Disord 32: 283-298.

11. White SW, Koenig K, Scahill L (2007) Social skills development in children with
Autism Spectrum Disorders: A review of the intervention research. J Autism Dev Disord 37: 1858-1868.

12. Reichow B, Volkmar FR (2010) Social skills interventions for individuals with autism: evaluation for evidence-based practices within a best evidence synthesis framework. J Autism Dev Disord 40: 149-166.

13. Cappadocia MC, Weiss J (2011) Review of social skills training groups for youth with Asperger Syndrome and High-Functioning Autism. Research in Autism Spectrum Disorders 5: 70-78.

14. Antshel KM, Polacek C, McMahon M, Dygert K, Spenceley L, et al. (2011) Comorbid ADHD and anxiety affect social skills group intervention treatment efficacy in children with Autism Spectrum Disorders. J Dev Behav Pediatr 32: 439-446.

15. Barry TD, Klinger LG, Lee JM, Palardy N, Gilmore T, et al. (2003) Examining the effectiveness of an outpatient clinic-based social skills group for highfunctioning children with autism. J Autism Dev Disord 33: 685-701.

16. Rao PA, Beidel DC, Murray MJ (2008) Social skills interventions for children with Asperger's syndrome or high-functioning autism: a review and recommendations. J Autism Dev Disord 38: 353-361.

17. Schreiber C (2010) Social skills interventions for children with High-Functioning Autism Spectrum Disorders. Journal of Positive Behavior Interventions 13: 4962.

18. Lopata C, Thomeer ML, Volker M, Nida RE (2006) Effectiveness of a CognitiveBehavioral Treatment on the social behaviors of children with Asperge Disorder. Focus on Autism and Other Developmental Disabilities 21: 237-244.

19. Lopata Christopher Thomeer ML, Volker M, Toomey J, Nida RE, et al. (2010) RCT of a manualized social treatment for High-Functioning Autism Spectrum Disorders. J Autism Dev Disord 40: 1297-1310.

20. Stichter JP, O'Connor KV, Herzog MJ, Lierheimer K, McGhee SD (2012) Socia competence intervention for elementary students with Aspergers syndrome and high functioning autism. J Autism Dev Disord 42: 354-366.

21. Bauminger N (2007) Brief report: group social-multimodal intervention for HFASD. J Autism Dev Disord 37: 1605-1615.

22. Solomon M, Goodlin-Jones BL, Anders, TF (2004) A social adjustment enhancement intervention for High-Functioning Autism, Asperger's Syndrome and Pervasive Developmental Disorder NOS. J Autism Dev Disord 34: 649668.

23. Cotugno AJ (2009) Social competence and social skills training and intervention for children with Autism Spectrum Disorders. J Autism Dev Disord 39: 12681277.

24. Kazdin AE (2008) Evidence-based treatment and practice: new opportunities to bridge clinical research and practice, enhance the knowledge base, and improve patient care. Am Psychol 63: 146-159.

25. Smith-Boydston JM, Nelson TB (2008) Adoption of evidence-based treatments in community settings: Obstacles and opportunities. In: Steele RG, David Elkin T, Roberts M (Eds.), Handbook of Evidence-Based Therapies for Children and Adolescents: Bridging Science and Practice. Springer, New York, pp. 521-535.

26. Weisz JR, Hawley KM, Pilkonis PA, Woody SR, Follette WC (2000) Stressing the (other) three Rs in the search for empirically supported treatments Review procedures, research quality, relevance to practice and the public interest. Clinical Psychology: Science and Practice 7: 243-258.

27. Rogers SJ (2000) Interventions that facilitate socialization in children with autism. J Autism Dev Disord 30: 399-409.

28. DeRosier ME, Swick DC, Davis NO, McMillen JS, Matthews R (2011) The efficacy of a social skills group intervention for improving social behaviors in children with High-Functioning Autism Spectrum Disorders. J Autism Dev Disord 41: 1033-1043.

29. Masten AS, Wright MO (2009) Resilience over the lifespan. In: Reich JW (Edr.) Handbook of Adult Resilience PP. 213-237.

30. Alvord MK, Grados JJ (2005) Enhancing resilience in children: A proactive approach. Professional Psychology: Research and Practice 36: 238-245.

31. Alvord MK, Zucker B, Grados JJ (2011) Resilience Builder Program for children and adolescents: Enhancing social competence and self-regulation. Research Press, Champaign, IL.

32. Reynolds CR and Kamphaus RW (2004) Behavior Assessment System for Children, $\left(2^{\text {nd }}\right.$ Edn) American Guidance Service, USA. 
Citation: Aduen PA, Rich BA, Sanchez L, O'Brien K, Alvord MK (2014) Resilience Builder Program Therapy Addresses Core Social Deficits and Emotion Dysregulation in Youth with High-Functioning Autism Spectrum Disorder. J Psychol Abnorm Child 3: 118. doi:10.4172/23299525.1000118

Page 10 of 10

33. Gresham F.M. and Elliott GR (2008) Social Skills Improvement System Rating Scales Manual. Minneapolis, MN: NCS Pearson. Journal of Psychoeducational Assessment 29: 292-296.

34. Erdlen RJ and Rickrode MR (2007) Social skills groups with youth: A cognitivebehavioral perspective. In: Handbook of Cognitive-Behavior Group Therapy with Children and Adolescents, R.W.Christner, J. Stewart, \& A. Freeman (Eds.) Routledge, New York, USA.

35. Walden TA, Harris VS, and Catron TF (2003) How I Feel: A self-report measure of emotional arousal and regulation for children. Psychological Assessment, 15: $399-412$.

36. Epstein NB, Baldwin LM and Bishop DS (1983) The McMaster Family Assessment Device. Journal of Marital Therapy 9: 171-180.

37. Kabacoff RI, Miller I, Bishop DS, Epstein NB and Keitner GI (1990) A psychometric study of the McMaster Family Assessment Device in psychiatric medical and non-clinical samples. Journal of Family Psychology 3: 431-439.
38. Rich BA, Nigro C, Watson C, Rosen HR, Sanchez L, et al. (2013b) Improved functioning in children with attention deficit hyperactivity disorder following treatment with the Resilience Builder Program ${ }^{\circledR}$ in a clinical service setting. Manuscript submitted for publication.

39. Watson C, Rich BA, Rosen HR, Sanchez L, O'Brien K, et al. (2013) Effectiveness of resilience-based group therapy for improving the functioning of anxious children 43: 269-286

40. White SW, Roberson-Nay R (2009) Anxiety, social deficits, and loneliness in youth with autism spectrum disorders. J Autism Dev Disord 39: 1006-1013.

41. Barrington J, Prior M, Richardson M, Allen K (2005) Effectiveness of CBT versus standard treatment for childhood anxiety disorders in a community clinic setting. Behaviour Change 22: 29-43.

42. Sim L, Whiteside SP, Dittner CA, Mellon M (2006) Effectiveness of a social skills training program with school age children: Transition to a clinical setting. Journal of Child and Family Studies 15: 408-417. 